\title{
Antenatal counseling in maternal and newborn care: use of job aids to improve health worker performance and maternal understanding in Benin
}

\author{
Larissa Jennings ${ }^{12^{*}}$, André Sourou Yebadokpo ${ }^{3}$, Jean $\mathrm{Affo}^{3}$, Marthe Agbogbe ${ }^{3}$
}

\begin{abstract}
Background: Antenatal care provides an important opportunity to improve maternal understanding of care during and after pregnancy. Yet, studies suggest that communication is often insufficient. This research examined the effect of a job aids-focused intervention on quality of counseling and maternal understanding of care for mothers and newborns.
\end{abstract}

Methods: Counseling job aids were developed to support provider communication to pregnant women. Fourteen health facilities were randomized to control or intervention, where providers were trained to use job aids and provided implementation support. Direct observation of antenatal counseling sessions and patient exit interviews were undertaken to assess quality of counseling and maternal knowledge. Providers were also interviewed regarding their perceptions of the tools. Data were collected before and after the job aids intervention and analyzed using a difference-in-differences analysis to quantify relative changes over time.

Results: Mean percent of recommended messages provided to pregnant women significantly improved in the intervention arm as compared to the control arm in birth preparedness (difference-in-differences $\left[\Delta_{1-c}\right]=+17.9$, 95\%Cl: 6.7,29.1), danger sign recognition $\left(\Delta_{\mathrm{I}-\mathrm{C}}=+26.0,95 \% \mathrm{Cl}\right.$ : $\left.14.6,37.4\right)$, clean delivery $\left(\Delta_{\mathrm{I}-\mathrm{C}}=+21.7,95 \% \mathrm{Cl}\right.$ : 10.9,32.6), and newborn care $\left(\Delta_{\mathrm{I}-\mathrm{C}}=+26.2,95 \% \mathrm{Cl}\right.$ : 13.5,38.9). Significant gains were also observed in the mean percent of communication techniques applied $\left(\Delta_{1-C}=+28.8,95 \% \mathrm{Cl}: 22.5,35.2\right)$ and duration (minutes) of antenatal consultations $\left(\Delta_{\mathrm{I}-\mathrm{C}}=+5.9,95 \% \mathrm{Cl}: 3.0,8.8\right)$. No relative increase was found for messages relating to general prenatal care $\left(\Delta_{1-\mathrm{C}}=+8.2,95 \% \mathrm{Cl}:-2.6,19.1\right)$. The proportion of pregnant women with correct knowledge also significantly improved for birth preparedness $\left(\Delta_{\mathrm{I}-\mathrm{C}}=+23.6,95 \% \mathrm{Cl}\right.$ : 9.8,37.4), danger sign recognition $\left(\Delta_{\mathrm{I}-\mathrm{C}}=+28.7,95 \% \mathrm{Cl}\right.$ : 14.2,43.2), and clean delivery $\left(\Delta_{-\mathrm{C} C}=+31.1,95 \% \mathrm{Cl}: 19.4,42.9\right)$. There were no significant changes in maternal knowledge of general prenatal $\left(\Delta_{\mathrm{I}-\mathrm{C}}=-6.4,95 \% \mathrm{Cl}\right.$ : $\left.-21.3,8.5\right)$ or newborn care $\left(\Delta_{\mathrm{I}-\mathrm{C}}=+12.7,95 \% \mathrm{Cl}:-6.1,31.5\right)$. Job aids were positively perceived by providers and pregnant women, although time constraints remained for health workers with other clinical responsibilities.

Conclusions: This study demonstrates that a job aids-focused intervention can be integrated into routine antenatal care with positive outcomes on provider communication and maternal knowledge. Efforts are needed to address time constraints and other communication barriers, including introduction of on-going quality assessment for long-term sustainability.

\footnotetext{
* Correspondence: larissa@post.harvard.edu

'USAID Health Care Improvement Project, University Research Co., LLC, Bethesda, Maryland, USA

Full list of author information is available at the end of the article
} 


\section{Background}

Antenatal care provides an important opportunity to improve maternal understanding about pregnancy, childbirth, and care of the newborn. In addition to routine examination, screening, and treatment, the World Health Organization's focused antenatal care model recommends information and counseling be provided to all pregnant women in areas related to the health needs of the pregnant woman, birth and emergency preparedness, nutrition, preventative home practices, and support for care-seeking through danger sign recognition [1]. This includes advice that promotes the health of the mother and newborn during and following delivery. Relatively high coverage of antenatal care enables health care personnel to reinforce communication across visits [2].

Communication provided antenatally has been shown to be an effective strategy to improve maternal understanding and health practices $[3,4]$. Yet, in many developing countries, information is lacking on the intrinsic quality of communication, limiting one's ability to assess intervention effects [5]. Studies that have examined quality of antenatal counseling suggest that adequacy of information provided is low - with less information-sharing than guidelines recommend [6-8]. Available data suggests that patients often perceive counseling to be poor [9], and low maternal knowledge following counseling has been attributed to insufficient communication [10-12].

There is a growing need for implementation research in developing countries that examines content of antenatal communication and effective strategies to improve maternal and newborn care counseling. Such interventions hold promise for reducing maternal and neonatal mortality in resource-poor settings. Traditional efforts to improve provider communication have often relied on resource-intensive strategies such as off-site training or continuing medical education [13]. However, recent evidence shows that job aids can serve as an acceptable, low-cost alternative to improve health worker performance when combined with minimal training and supervision [14-18]. Job aids are support tools with written information that is often enhanced by images, making readily available information needed to comply with standards while minimizing provider dependence on memory $[19,20]$. In the context of counseling, pictorial job aids can strengthen communication by helping providers to remember key messages [21]. They may also function to facilitate communication processes by conveying ideas using imagery [22,23]. Job aids have been shown to be effective in areas such as malaria $[14,15]$, infant feeding $[16,24]$, and family planning $[17,18]$. Evidence is needed to examine use of job aids to improve antenatal communication in maternal and newborn care.

This study uses implementation research to assess quality of counseling provided to pregnant women and the impact of a job aids-focused intervention consisting of training, organizational change, and field support on provider communication and, in turn, maternal understanding. The study hypothesized that the quality of job aid-supported counseling would be better than that of counseling which was not supported, and that better counseling would yield higher levels of maternal understanding.

\section{Methods \\ Study Design and Context}

This study used a pre-post randomized group design. Data were collected from August to October 2008 in the Zou/Collines region of Benin. Antenatal care coverage is high in Benin and represents an ideal time to advise pregnant women. An estimated $88 \%$ of Beninese women receive at least one antenatal care visit, and $61 \%$ receive at least four visits [25]. Fourteen public health maternities were randomized to the intervention or control group. Women in the intervention group received counseling by nurse-midwives specifically trained in use of the job aids. Women in the control group received the usual care and advice. Data were obtained before and after introduction of the job aids in both control and intervention arms, yielding four cross-sectional groups.

\section{Sample selection}

The target sample for each group was 154 pregnant women, sufficient to detect a mean difference of $15 \%$ percentage points in quality scores and proportional difference of $25 \%$ in maternal knowledge between groups at $80 \%$ power with an incompletion rate of $10 \%$ and a design effect of 2.0. Several public health centers were selected to achieve the target sample size and improve generalizability of results across sites, providers, and clients. All pregnant women presenting for antenatal consultation during the study period were eligible to participate. Using systematic sampling, eligible women were approached while waiting for consultation, given information regarding the purpose of the study, and invited to participate. As part of the information process, women were assured confidentiality and that opting out would not compromise the care they would receive. Participation from site managers and providers was obtained prior to the start of the study.

\section{Job Aids}

The job aids developed in this study were a set of pictorial counseling cards designed to support communication to women about care during and after pregnancy according to national guidelines [Figure 1]. Generic counseling cards and counseling materials for maternal and newborn care were used as a basis for their design 


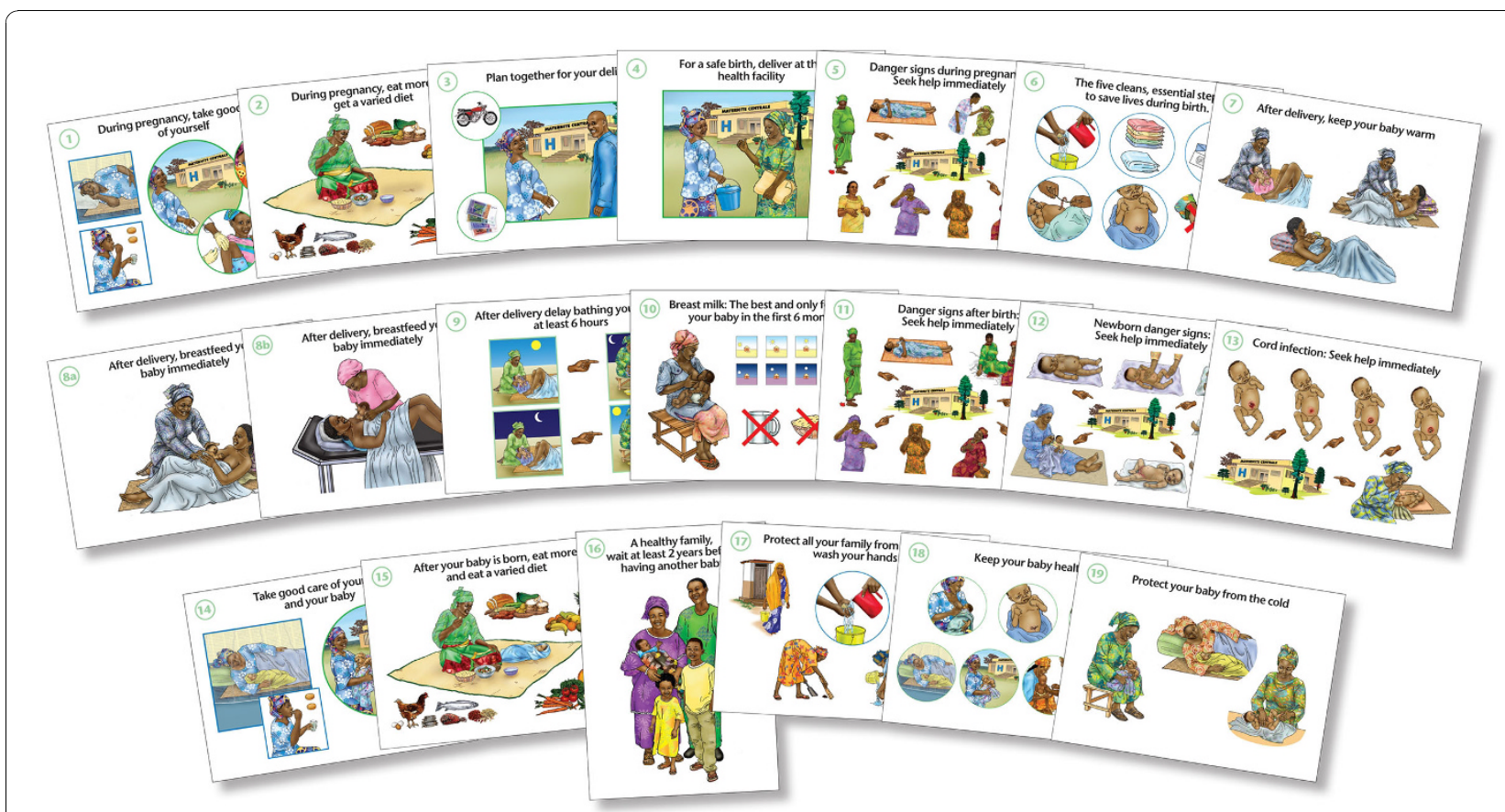

Figure 1 Counseling job aids used for communication regarding pregnancy care, birth preparedness and maternal danger signs Actual size $8 \times 11$ (A1 sheet)

by the USAID Quality Assurance Project (QAP) and the Integrated Family Health Project Health Project (PISAF), both managed by University Research Co., LLC (URC), in collaboration with the Benin Ministry of Health. Culturally appropriate images were designed based on community and subject expert feedback as well as a pilot field study. One side of the counseling card provided guidance to the provider on key messages to convey (the "job aid"). The other side of the card was a pictorial guide for the client that used illustrations to portray core messages (the "visual aid"). The overall objective of the counseling cards was to support information-sharing by the provider, enhance the transfer of knowledge to women, and depict recommended health behaviors.

Eleven antenatal cards were organized into three modules that prioritized messages according to a woman's stage of pregnancy (early, mid-, or late) to ensure that over the course of pregnancy, a woman would have multiple exposures to key messages. Module A consisted of five cards for women in early pregnancy and included messages on general pregnancy care, birth and emergency preparedness, maternal danger signs, and clean delivery. Module B consisted of four cards for women at mid-pregnancy with information on newborn care, such as immediate and exclusive breastfeeding, delayed bathing, and thermal protection. Module $\mathrm{C}$ consisted of two cards for women in late pregnancy that reinforced key aspects of maternal and newborn care. In Benin, counseling on immediate newborn care is typically performed postnatally. However, in this study, counseling on newborn care was additionally piloted antenatally in intervention sites for women in mid-to-late pregnancy. Verification of the content of Module A or Modules A and $B$ was a prerequisite for introduction of the next module.

\section{Description of Intervention}

Introduction of the job aids consisted of three intervention components: training, organizational changes, and field support. All health care personnel at the intervention sites were trained for three days in the content and use of the counseling cards, interpersonal communication, and quality improvement. The training included role-playing and didactic instruction with available written materials, such as a technical reference guide and other documents.

The role-playing used two methods: one-on-one roleplaying with feedback from the trainer and role-playing in plenary with feedback from peers. Providers practiced conducting a counseling session with the counseling cards following a 10-step process: (1) present the topic to be discussed; (2) ask the woman what she already knows about the topic; (3) present the counseling card; (4) ask the woman what she sees on the card; (5) encourage the woman to describe what message she thinks 
the card conveys; (6) based on the woman's response, elaborate on messages using images provided on the card; (7) verify the woman's understanding by asking her to summarize key points; (8) encourage her to ask questions; (9) summarize any remaining messages; and (10) check the back of the card to be sure all messages have been discussed. Providers applied this process in using the counseling job aids for any one of the three modules.

At the end of the training session, participants in each site formed a team to identify organizational changes needed to implement job-aid supported counseling at their site, such as ensuring the availability of the cards, organizing them into modules, assigning roles, or in sites where group counseling was provided - stratifying sessions by pregnancy stage to reduce group sizes. Teams also convened an on-site organizational meeting to build consensus on the new communication strategy and to further identify best practices for organizing counseling at their site. Prior to data collection, all sitelevel teams received a supervisory visit from one of the counseling instructors and/or technical advisors. These visits included direct observation of antenatal consultations using the job aids with immediate feedback and technical support, as well as open discussion about difficulties encountered during implementation. The posttraining field visits aimed to assist health workers in overcoming communication barriers and strengthen overall communication processes. None of the three intervention components were introduced to providers in the control arm. Usual care and advice in these sites did not consist of job aids or targeted communication based on stage of pregnancy.

\section{The Improvement Context}

Several participating sites (five in the control arm and four in the intervention arm) were concurrently engaged in a quality improvement collaborative to strengthen clinical care in management of normal deliveries and obstetric complications. A collaborative is an improvement strategy that engages a group of health workers at various sites to jointly improve quality of care for a specific technical area through cross-sharing of organizational learning and best practices [26]. The improvement collaborative included prior technical training of skilled providers in essential obstetric and newborn care who met quarterly during "learning sessions" to discuss best practices. Although the collaborative improved many clinical aspects of care, no efforts had been made to address counseling to women during antenatal consultations. Thus, while study sites had varying quality improvement experiences (e.g., collaborative versus non-collaborative), they were comparable in their limited focus on strengthening counseling to women on maternal and newborn care. To improve generalizability, the job aids were introduced to both types of sites, and intervention components targeted competencies relating to communication regardless of participation in the clinical collaborative.

\section{Measurement}

This study measured three outcomes: (1) quality of counseling provided to pregnant women; (2) provider perceptions regarding use of the job aids; and (3) women's knowledge of messages relating to maternal and newborn care.

To evaluate quality of counseling, the content of communication and counseling technique used by the provider were measured through direct observation using a pre-tested observation checklist developed by the study team for this purpose. The checklist contained items categorized in five topic areas: general prenatal care, birth preparedness, dangers signs, clean delivery, and newborn care. "General prenatal care" included four messages relating to prevention and treatment of malaria (use of an insecticide-treated mosquito net and antimalarials), iron/folate supplementation, having at least four antenatal visits, and diet and nutrition. "Birth preparedness" included seven messages on identifying a place of delivery, identifying a skilled birth attendant, organizing transportation, setting money aside, planning for emergencies, planning with a family member, and identifying a blood donor. "Danger signs" highlighted nine maternal symptoms that require care: vaginal bleeding, convulsions, fever, water loss, abdominal pains, severe headaches, blurred vision, swelling of limbs, and absence of or diminished fetal movement. "Clean delivery" consisted of two messages relating to providing a clean, plastic cloth for delivery and clean, dry towels for the mother and newborn. Six messages related to "newborn care": skinto-skin contact, early breastfeeding, exclusive breastfeeding, delayed bathing, clean cord care, and thermal protection. For each item, the trained observer selected 'yes' (coded as 1) or 'no' (coded as 0 ) depending on whether the woman received information on that item during her antenatal visit. The mean percent of messages provided for each group was calculated based on the number of messages provided to a woman within each category out of the total number of recommended messages. All messages provided during group and/or individual sessions were included to represent overall communication during each woman's antenatal visit. Provider communication techniques were scored similarly across six communication techniques: presentation of the subject, posing of questions to determine current knowledge, use of visual aid(s), verification of understanding, motivation to adapt behaviors, and asking the woman if she had questions. Information on the context of the session was also collected, such as the mode of communication (e.g., group 
or individual), session duration, and primary language used.

Provider perceptions on use of the counseling cards were examined only in the intervention arm and after implementation of the job aids. Data were obtained using individual interviews. Each health worker was asked four questions (one closed and three open-ended): whether she thought the counseling job aids should be introduced in other sites to support communication; what she considered to be advantages and disadvantages in using the job aids; and what recommendations, if any, she had to improve their overall use and effectiveness. Responses were coded and analyzed by topic area. Information on provider demographic characteristics, such as age, education, qualification, years working at site, and years working in public health, was also obtained.

To assess maternal understanding, pregnant women were interviewed at the clinic prior to departure. Structured questionnaires were written in French and administered orally in the local language, Fon. Women were asked to indicate what they considered to be important components of care during and after pregnancy for the mother and newborn as well as what they considered to be danger signs that required urgent medical care. On average, exit interviews took 30 to 45 minutes to complete. Also obtained were the woman's age, months in pregnancy, education, number of previous antenatal visits, first-time visit status, and number of living children.

Pre-intervention data were obtained in August 2008, and post-intervention data were obtained in October 2008, three weeks following the introduction of the intervention. All data collection tools were reviewed and approved by local Beninese project staff to make sure they were clear, easy to follow, appropriate, and relevant for the local culture. The observation team received three days of training in counseling observation, interviewer techniques, and questionnaire completion, including a standardization session to minimize interobserver variability. Pre-tested, standardized questionnaires with a detailed guide for data collectors were used with routine supervision of data collectors' instruments. Supervisors observed approximately $5 \%$ of counseling sessions and patient interviews for quality control and validation purposes.

\section{Statistical Analysis}

Data were analyzed using STATA (Version 9.2, StataCorp, College Station, TX). Difference-in-differences analyses within multivariate linear regressions were used to account for differences in baseline quality of counseling between intervention and control groups based on an interaction term of study arm and time. In difference-in-differences analyses, the coefficient of the interaction term and its subsequent $95 \%$ confidence interval
(CI) represent the difference in the change over time in the intervention group as compared to the change over time in the control group [27]. As a result, calculation of the intervention's effect size is adjusted for differences over time in the control arm [28].

Additionally, the study employed three-level hierarchal modeling techniques to account for the inherent correlation of observations. Pregnant women (level 1) were nested within providers (level 2) who were nested within sites (level 3). Hierarchal regression models are more suitable for clustered data than conventional regression analyses that underestimate standard errors by assuming that observations from the same sites or providers are independent [29]. Random effects were incorporated for provider- and site-level characteristics, and fixed effects were incorporated for patient characteristics that significantly varied between groups. Random effects hierarchal analyses aim to correct for correlation of observations and account for unmeasured differences in level-specific characteristics [30]. This technique was used since a means-as-outcomes regression model indicated that no site or provider characteristics had significant direct effects on quality of communication.

Maternal knowledge was measured based on the proportion of women with knowledge of at least three items within each topic area. Similar to analyses of quality of counseling, mixed hierarchal regression models using difference-in-difference analyses were used to adjust for nesting of observations and baseline level differences. This was coupled with multivariate analyses to control for confounding. Data were double entered using EpiData (Version 3.2) with automatic checks for quality control. In all analyses, the level of significance was considered at $p \leq 0.05$.

\section{Ethics Approval}

This study received ethics approval by the Johns Hopkins Bloomberg School of Public Health Institutional Review Board, Baltimore, Maryland; the Research \& Evaluation review group of the USAID Health Care Improvement Project at University Research Co., LLC (URC), Bethesda, Maryland; and the USAID Integrated Family Health Project at URC, Bohicon, Benin.

\section{Results}

\section{Demographic characteristics}

Table 1 presents demographic characteristics of the study population. Antenatal consultations of 686 pregnant women were observed followed by exit interviews: 211 in the baseline intervention arm, 204 in endline intervention, 119 in baseline control, and 152 in endline control. This represented 55 providers: 26 and 29 in the intervention and control arms, respectively, although not all providers were available during both periods of 
Table 1 Characteristics of study sample

\begin{tabular}{|c|c|c|c|c|c|}
\hline & \multirow[t]{2}{*}{ Total } & \multicolumn{2}{|c|}{ Intervention Arm } & \multicolumn{2}{|c|}{ Control Arm } \\
\hline & & Pre- & Post- & Pre- & Post- \\
\hline \multicolumn{6}{|l|}{ Study Population } \\
\hline Number of sites & 14 & 7 & 7 & 7 & 7 \\
\hline Total number of observations & 686 & 211 & 204 & 119 & 152 \\
\hline Total number of providers & 55 & 20 & 21 & 25 & 25 \\
\hline Counseled only at baseline & 9 & 5 & 0 & 4 & 0 \\
\hline Counseled only at endline & 10 & 0 & 6 & 0 & 4 \\
\hline Counseled at baseline + endline & 36 & 15 & 15 & 21 & 21 \\
\hline Group and individual counseling (\%) & 55.7 & 58.2 & 79.9 & 35.9 & 33.6 \\
\hline Group counseling only (\%) & 1.3 & 0 & 4.4 & 0 & 0.7 \\
\hline Individual counseling only (\%) & 43.0 & 41.8 & 15.7 & 64.1 & 65.8 \\
\hline \multicolumn{6}{|l|}{ Provider Characteristics } \\
\hline Skilled provider type (\%) & 86.5 & 83.3 & 95.2 & 92.0 & 87.5 \\
\hline Mean age (yrs) & 34.6 & 35.3 & 33.6 & 34.4 & 34.2 \\
\hline Completed secondary education (\%) & 96.2 & 100 & 100 & 100 & 92 \\
\hline Years working in health field (yrs) & 9.7 & 11.1 & 10.1 & 8.5 & 8.2 \\
\hline Years working at health center (yrs) & 4.1 & 4.8 & 4.6 & 2.9 & 3.7 \\
\hline \multicolumn{6}{|l|}{ Patient Characteristics } \\
\hline Mean age (yrs) & 25.8 & 25.6 & 25.4 & 26.0 & 26.6 \\
\hline Mean gestational age (months) & 5.9 & 5.9 & 6.0 & 5.9 & 5.8 \\
\hline Educational status (\%, > 8 yrs) & 52.9 & 60.0 & 52.0 & 52.9 & 44.1 \\
\hline $1^{\text {st }}$ prenatal visit (in current pregnancy) & 30.0 & 28.4 & 23.5 & 36.1 & 36.2 \\
\hline Mean no. of ANC visits (in current pregnancy) & 2.6 & 2.8 & 2.8 & 2.5 & 2.4 \\
\hline Mean number of living children & 1.7 & 1.6 & 1.6 & 1.8 & 1.9 \\
\hline
\end{tabular}

data collection. On average, there were 3.9 providers per site; 49 pregnant women were observed at each site; and 12.4 women were observed for each provider. The sample size in the control arm is smaller given the lower-than-expected number of women presenting for antenatal consultation in these sites. Approximately $4 \%$ of providers working in the study's maternities were not enrolled because they were not working at the clinic during the time of study and were logistically unable to participate in study activities. Non-participation of women was observed to be rare as women were willing and interested in discussing care for themselves and their newborns. Although there were no differences in provider characteristics between study arms with respect to age, qualification, education, years working in public health, and years working at the site, group education followed by individual counseling was more common in the intervention arm in pre- and post-groups $(58 \%$ and $80 \%$ ) than the control arm (36\% and $34 \%)$ as compared to only group or individual counseling.

The groups of pregnant women in the intervention and control arms prior to and after the intervention were similar with respect to age, months in pregnancy, number of antenatal visits, and number of living children. Women's characteristics differed by education status and first antenatal visit. Over half of the women in the baseline intervention arm $(60 \%)$ had more than eight years of schooling compared to $52 \%, 53 \%$, and $44 \%$ in the endline intervention, baseline control, and endline control groups, respectively. The proportion of women presenting at their first antenatal visit in the current pregnancy was higher in the control groups $(36 \%$ and $36 \%)$ than in the intervention groups $(28 \%$ and 24\%). Mean gestational age for first-time attendees was 4.1 months across all groups (data not shown) compared to 5.9 months for the total study population. Of the observed consultations, $81 \%$ were conducted in Fon, 9\% in Nagot, 2\% in French, and 8\% in other local languages (data not shown).

\section{Content of Communication}

Table 2 presents changes over time in the mean percent of recommended messages provided to pregnant women by topic and study arm. On average, pregnant women in the intervention and control arm received $51 \%$ and $36 \%$, respectively, of recommended maternal and newborn care messages during antenatal consultations at baseline. Relative improvement $\left(\Delta_{I}-\Delta_{c}\right)$ in the mean percent of messages provided in the intervention arm was +19.6 (95\% CI: 12.2, 26.9) in adjusted analyses, accounting for 
Table 2 Changes in mean percent of messages provided during antenatal visit by topic and study arm

\begin{tabular}{|c|c|c|c|c|c|c|c|}
\hline \multirow[t]{2}{*}{ Mean $\%$ of messages provided } & \multicolumn{3}{|c|}{ Intervention Arm } & \multicolumn{3}{|c|}{ Control Arm } & \multirow{2}{*}{$\begin{array}{l}\text { Difference in differences } \\
\Delta_{\mathrm{i}}-\Delta_{\mathrm{c}}(95 \% \mathrm{Cl})\end{array}$} \\
\hline & Pre- & Post- & Differ-ence $\left(\Delta_{\mathrm{i}}\right)$ & Pre- & Post- & Differ-ence $\left(\Delta_{c}\right)$ & \\
\hline No. of pregnant women & 211 & 204 & & 119 & 152 & & \\
\hline \multicolumn{8}{|l|}{ Adjusted Scores ${ }^{a}$} \\
\hline Mean $\%$ of messages given (total) & 51.4 & 67.9 & +16.5 & 35.5 & 32.4 & -3.1 & $+19.6(12.2,26.9)$ \\
\hline \multicolumn{8}{|l|}{ Mean $\%$ of messages given (by topic ${ }^{b}$ ) } \\
\hline Prenatal Care & 64.5 & 68.6 & +4.1 & 51.4 & 47.4 & -4.1 & $+8.2(-2.6,19.1)$ \\
\hline Birth preparedness & 53.7 & 66.5 & +12.9 & 40.5 & 35.4 & -5.1 & $+17.9(6.7,29.1)$ \\
\hline Danger signs during pregnancy & 38.8 & 63.5 & +24.7 & 24.4 & 23.1 & -1.3 & $+26.0(14.6,37.4)$ \\
\hline Clean delivery & 49.1 & 70.4 & +21.3 & 15.1 & 14.7 & -0.4 & $+21.7(10.9,32.6)$ \\
\hline Newborn care ${ }^{c}$ & 20.6 & 49.3 & +28.7 & 3.8 & 6.3 & +2.5 & $+26.2(13.5,38.9)$ \\
\hline Mean \% of communication techniques used & 46.2 & 75.4 & +29.2 & 42.7 & 43.0 & +0.3 & $+28.8(22.5,35.2)$ \\
\hline Mean duration of antenatal consultation ${ }^{d}$ & 18.3 & 23.9 & +5.6 & 15.8 & 15.5 & -0.3 & $+5.9(3.0,8.8)$ \\
\hline
\end{tabular}

[a] Scores adjusted for differences at baseline and correlation of observations; site- and provider-level characteristics (random effects); counseling mode; and patient age, education, first antenatal visit, and total number of antenatal visits (fixed effects). [b] Total number of messages by category include: prenatal care ( $\mathrm{n}$ $=5)$, birth preparedness $(n=7)$, danger signs during pregnancy $(n=9)$; clean delivery $(n=2)$; newborn care $(n=6)$; communication techniques $(n=6)$. [c] Includes only women at 6 - 9 months of pregnancy. [d] Excludes additional time for women who participated in individual counseling following group session.

clustering and differences in site-, provider- and patientlevel characteristics. By topic area, relative improvements in the intervention arm were observed in four out of five topics: birth and emergency preparedness $\left(\Delta_{\mathrm{I}}-\Delta_{\mathrm{C}}=+17.9,95 \% \mathrm{CI}: 6.7,29.1\right)$, danger signs during pregnancy $\left(\Delta_{\mathrm{I}}-\Delta_{\mathrm{c}}=+26.0,95 \%\right.$ CI: 14.6, 37.4), clean delivery $\left(\Delta_{\mathrm{I}}-\Delta_{\mathrm{c}}=+21.7,95 \% \mathrm{CI}: 10.9,32.6\right)$, and for women with advanced pregnancy, newborn care $\left(\Delta_{\mathrm{I}}-\Delta_{\mathrm{C}}=+26.2,95 \%\right.$ CI: $\left.13.5,38.9\right)$. In the area of general prenatal care, modest gains in communication in both study arms were observed with no significant relative improvement $\left(\Delta_{\mathrm{I}}-\Delta_{\mathrm{C}}=+8.2,95 \% \mathrm{CI}:-2.6,19.1\right)$.

Table 3 presents an item analysis of key messages provided within all five topic areas. The overall proportion of women receiving communication varied from message to message. In the intervention arm, the largest improvements were observed among messages relating to identification of a skilled birth attendant, emergency planning, provision of a plastic cloth (for clean delivery) and messages relating to newborn care such as early and exclusive breastfeeding and delayed bathing. Messages with relatively high scores at baseline and only modest improvements at endline included taking antimalarials, information on nutrition for pregnant women, placing money aside, and planning for birth with a family member. No significant improvements were observed for messages concerning use of an insecticidetreated mosquito net or iron/folate supplementation during pregnancy. In the control arm, no significant changes were observed between baseline and endline.

\section{Communication Techniques and Duration}

Overall mean performance in communication techniques of health providers was $46 \%$ and $43 \%$ at baseline in intervention and control arms, respectively (Table 2). The relative mean percent of communication techniques used was significant in the intervention arm $\left(\Delta_{\mathrm{I}}-\Delta_{\mathrm{c}}=\right.$ +28.8 , 95\% CI: 22.5, 35.2). At the item level, providers presented the subject to be discussed in the majority of consultations, and baseline measures of techniques such as posing questions to ascertain current knowledge, verification of understanding, and asking the woman if she had questions were observed at moderate levels in intervention and control arms. These techniques (as well as others that were used less frequently) remained unchanged in the control arm, but increased significantly in the intervention arm. The two most notable increases in techniques used were use of a visual aid the intervention's counseling job aids - and verification of understanding, which included a summary of key messages following the consultation.

These improvements were associated with increases in consultation duration. Each session lasted an average 18 minutes at baseline in both study arms and significantly increased to 24 minutes in the intervention $\operatorname{arm}\left(\Delta_{\mathrm{I}}-\Delta_{\mathrm{c}}=\right.$ +5.9 , 95\% CI: 3.0, 8.8). The observed additional time appears to have been associated with increased communication, although time spent in clinical examination versus communication was not measured systematically.

\section{Maternal Knowledge}

Improvements in knowledge among pregnant women were observed in the area of birth preparedness, recognition of danger signs, and clean delivery after controlling for differences at baseline, correlation of data, and levelspecific characteristics (Table 4). At baseline, $21 \%$ and $26 \%$ of pregnant women in the intervention and control arm, respectively, could correctly identify at least three 
Table 3 Item analysis - percent women provided with any message during antenatal visit, by topic and study arm

\begin{tabular}{|c|c|c|c|c|c|c|c|c|}
\hline & \multicolumn{3}{|c|}{ Intervention Arm } & \multicolumn{3}{|c|}{ Control Arm } & \multicolumn{2}{|c|}{ Difference in differences } \\
\hline & Pre- & Post- & Differ-ence $\left(\Delta_{\mathrm{i}}\right)$ & Pre- & Post- & Differ-ence $\left(\Delta_{c}\right)$ & $\Delta_{\mathrm{i}}-\Delta_{\mathrm{c}}$ & $95 \% \mathrm{Cl}$ \\
\hline No. of women $(\mathrm{N}=686)$ & 211 & 204 & & 119 & 152 & & & \\
\hline \multicolumn{9}{|l|}{ Prenatal care } \\
\hline Sleep under a mosquito net & 76.3 & 74.0 & -2.3 & 66.4 & 74.3 & +8.0 & -10.2 & $(-23.8,3.4)$ \\
\hline Take antimalarials & 61.1 & 71.1 & +9.9 & 53.8 & 55.3 & +1.5 & +8.4 & $(-6.4,23.3)$ \\
\hline Take iron/folic supplements & 79.6 & 75.5 & -4.1 & 63.0 & 67.8 & +4.7 & -8.9 & $(-22.5,4.7)$ \\
\hline Have at least 4 prenatal visits & 31.8 & 65.7 & +33.9 & 21.0 & 29.6 & +8.6 & +25.3 & $(11.2,39.4)$ \\
\hline Eat more and more varied & 61.6 & 72.5 & +10.9 & 26.1 & 32.2 & +6.2 & +4.8 & $(-9.5,19.0)$ \\
\hline
\end{tabular}

Birth Preparedness

$\begin{array}{lllllllll}\text { Identify place of delivery } & 62.6 & 85.3 & +22.7 & 47.1 & 45.4 & -1.7 & +24.4 & (10.3,38.5) \\ \text { Identify means of transport } & 56.4 & 86.8 & +30.4 & 37.8 & 39.5 & +1.7 & +28.7 & (14.8,42.6) \\ \text { Identified skilled attendant } & 32.2 & 71.6 & +39.3 & 28.6 & 25.0 & -3.6 & +42.9 & (28.9,56.9) \\ \text { Put money aside } & 73.0 & 84.3 & +11.3 & 42.0 & 41.4 & -0.6 & +11.9 & (-1.8,25.6) \\ \text { Plan for emergency } & 40.3 & 80.9 & +40.6 & 28.6 & 30.3 & +1.7 & +38.9 & (25.0,52.8) \\ \text { Plan with family } & 70.1 & 84.3 & +14.2 & 47.1 & 48.7 & +1.6 & +12.5 & (-1.4,26.4) \\ \text { Identify a blood donor } & 50.7 & 68.6 & +17.9 & 30.3 & 28.3 & -2.0 & +19.9 & (5.3,34.4)\end{array}$

Danger signs during pregnancy

$\begin{array}{lllllllll}\text { Vaginal bleeding } & 51.2 & 71.1 & +19.9 & 27.7 & 32.9 & +5.2 & +14.7 & (0.2,29.3) \\ \text { Convulsions } & 15.2 & 53.9 & +38.7 & 4.2 & 7.9 & +3.7 & +35.0 & (23.6,46.5) \\ \text { Fever } & 53.1 & 71.6 & +18.5 & 32.7 & 32.2 & -0.5 & +19.0 & (4.4,33.6) \\ \text { Water loss } & 49.8 & 71.6 & +21.8 & 21.8 & 28.3 & +6.4 & +15.4 & (1.1,29.6) \\ \text { Abdominal pains } & 50.2 & 72.5 & +22.3 & 28.6 & 28.3 & -0.3 & +22.6 & (8.2,37.0) \\ \text { Severe headaches } & 36.0 & 68.1 & +32.1 & 21.8 & 25.0 & +3.2 & +29.0 & (14.9,43.0) \\ \text { Blurred vision } & 23.2 & 66.1 & +43.0 & 15.1 & 14.5 & -0.6 & +43.6 & (30.8,56.4) \\ \text { Swelling of limbs } & 35.1 & 57.4 & +22.3 & 14.3 & 13.8 & -0.5 & +22.8 & (9.3,36.2) \\ \text { Diminished fetal movement } & 29.9 & 57.4 & +27.5 & 10.1 & 18.4 & +8.3 & +19.2 & (5.8,32.5)\end{array}$

Clean Delivery

$\begin{array}{lllllllll}\text { Bring plastic cloth } & 27.5 & 66.7 & +39.2 & 0.8 & 2.6 & +1.8 & +37.4 & (26.1,48.7) \\ \text { Bring } 5 \text { clean towels } & 65.9 & 81.9 & +16.0 & 18.5 & 21.1 & +2.6 & +13.4 & (0.4,26.4)\end{array}$

Immediate newborn care ${ }^{a}$

$\begin{array}{lllllllll}\text { Skin-to-skin contact } & 21.5 & 46.7 & +25.1 & 4.4 & 5.7 & +1.3 & +23.8 & (8.2,39.3) \\ \text { Initiation of immediate BF } & 20.8 & 58.3 & +37.6 & 5.9 & 11.5 & +5.6 & +32.0 & (15.9,48.0) \\ \text { Avoid prelacteal foods/exclusive BF } & 9.2 & 55.0 & +45.8 & 5.9 & 10.3 & +4.4 & +41.3 & (26.7,55.9) \\ \text { Delayed bathing } & 3.1 & 41.7 & +38.6 & 2.9 & 2.3 & +0.6 & +39.2 & (27.0,51.5) \\ \text { Clean cord care } & 4.6 & 37.5 & +32.9 & 1.5 & 5.7 & +4.2 & +28.6 & (15.9,41.3) \\ \text { Thermal protection } & 19.2 & 48.3 & +29.1 & 2.9 & 8.0 & +5.1 & +24.0 & (8.6,39.4)\end{array}$

Communication Technique

\begin{tabular}{|c|c|c|c|c|c|c|c|c|}
\hline Presents the subject & 72.5 & 98.5 & +26.0 & 73.1 & 81.6 & +8.5 & +17.5 & $(6.3,28.8)$ \\
\hline $\begin{array}{l}\text { Poses questions to determine current } \\
\text { knowledge of pregnant woman }\end{array}$ & 61.1 & 99.0 & +37.9 & 54.6 & 59.9 & +5.2 & +32.6 & $(19.8,45.5)$ \\
\hline Uses cards or other visual aids & 28.4 & 99.5 & +71.1 & 16.8 & 19.7 & +2.9 & +68.1 & $(57.3,79.0)$ \\
\hline Verifies understanding & 55.0 & 98.5 & +43.6 & 52.9 & 61.8 & +8.9 & +34.7 & $(21.7,47.6)$ \\
\hline Motivates to adapt behaviors & 69.2 & 96.1 & +26.9 & 26.9 & 38.2 & +11.2 & +15.6 & $(3.1,28.1)$ \\
\hline Asks woman if she has questions & 72.0 & 97.1 & +25.0 & 50.4 & 59.2 & +8.8 & +16.2 & $(3.6,28.9)$ \\
\hline
\end{tabular}

[a] Includes only women at 6 - 9 months of pregnancy. 
Table 4 Changes in maternal knowledge by topic and study arm

\begin{tabular}{|c|c|c|c|c|c|c|c|}
\hline \multirow[t]{2}{*}{ Percentage (\%) of women with correct responses } & \multicolumn{3}{|c|}{ Intervention Arm } & \multicolumn{3}{|c|}{ Control Arm } & \multirow{2}{*}{$\begin{array}{l}\text { Difference in differences } \\
\Delta_{\mathrm{i}}-\Delta_{\mathrm{C}}(95 \% \mathrm{Cl})\end{array}$} \\
\hline & Pre- & Post- & $\left(\triangle_{\mathrm{i}}\right)$ & Pre- & Post- & $\left(\Delta_{c}\right)$ & \\
\hline No. pregnant women & 211 & 204 & & 119 & 152 & & \\
\hline \multicolumn{8}{|l|}{ Adjusted Scores $^{a}$} \\
\hline$\geq 3$ messages in prenatal care & 49.8 & 62.7 & +12.9 & 26.5 & 45.8 & +19.3 & $-6.4(-21.3,8.5)$ \\
\hline$\geq 3$ messages in birth preparedness & 20.5 & 47.9 & +27.4 & 25.7 & 29.5 & +3.8 & $+23.6(9.8,37.4)$ \\
\hline$\geq 3$ danger signs during pregnancy & 55.3 & 88.8 & +33.2 & 40.4 & 44.9 & +4.5 & $+28.7(14.2,43.2)$ \\
\hline$=2$ messages in clean delivery & 15.7 & 49.2 & +33.5 & 2.5 & 4.9 & +2.4 & +31.1 (19.4, 42.9) \\
\hline$\geq 3$ messages in newborn care ${ }^{b}$ & 32.5 & 57.7 & +25.2 & 21.4 & 33.9 & +12.4 & $+12.7(-6.1,31.5)$ \\
\hline Mean \# correct responses & 8.6 & 12.6 & +3.9 & 7.7 & 8.7 & +1.0 & $+2.9(1.9,3.9)$ \\
\hline
\end{tabular}

[a] Scores adjusted for differences at baseline and correlation of observations; site- and provider-level characteristics (random effects); counseling mode; and patient age, education, first antenatal visit, and total number of antenatal visits (fixed effects). [b] Includes only women at 6 - 9 months of pregnancy.

components of birth and emergency preparedness with a relative improvement in the intervention arm of +23.6 (95\% CI: 9.8, 37.4). There was also a significant relative improvement in the proportion of women who could identify at least three danger signs during pregnancy that needed the urgent attention of a health professional $\left(\Delta_{\mathrm{I}}\right.$ $\Delta_{\mathrm{c}}=+28.7,95 \%$ CI: 14.2, 43.2). Signs such as abdominal pains $(92 \%)$, fever $(88 \%)$, and heavy bleeding $(79 \%)$ were most commonly reported by women in the intervention arm (not shown). A relatively lower proportion of women indicated water loss (68\%), blurred vision (34\%), or absent or diminished fetal movement (24\%) as a danger sign. Convulsions (21\%) and swelling of the limbs (13\%) were least commonly considered indicative of danger (data not shown). Significant relative improvements were also observed for correct knowledge of both clean delivery items $\left(\Delta_{\mathrm{I}}-\Delta_{\mathrm{c}}=+31.1,95 \%\right.$ CI: $\left.19.4,42.9\right)$. No significant relative improvement was observed in maternal knowledge regarding general prenatal care $\left(\Delta_{\mathrm{I}}-\Delta_{\mathrm{c}}=\right.$ $-6.4,95 \%$ CI: $-21.3,8.5)$ or newborn care $\left(\Delta_{\mathrm{I}}-\Delta_{\mathrm{c}}=+12.7\right.$, 95\% CI: -6.1, 31.5). As compared to the control arm, the overall mean number of correct responses across all topic areas improved significantly in the intervention arm $\left(\Delta_{\mathrm{I}}-\Delta_{\mathrm{C}}=+2.9,95 \%\right.$ CI: $\left.1.9,3.9\right)$.

\section{Provider Perceptions}

Table 5 lists provider perceptions regarding use of the counseling job aids within three topic areas: perceived advantages, perceived disadvantages, and suggestions to improve overall use and effectiveness. The three most commonly reported advantages to using the aids were that they helped women retain information given the images of key signs or practices; they helped the provider remember what topics to discuss during the antenatal session; and the perceived time required for explaining a practice was less since the images well depicted the desired communication goal. Providers using the counseling job aids also noted that having them allowed workers to improve their skills over time and that women presenting at the clinics also appreciated and showed interest in the counseling cards.

On the other hand, providers remarked that the required additional time to use all of the counseling cards in a given module, including verification of prior knowledge in preceding modules, was a disadvantage that delayed women's departure from the antenatal clinic. Some providers suggested that the number of counseling cards be decreased in tandem with an increase in the number of messages per card while improving their durability as well from the original laminated format. A few workers proposed that the training session be extended from its current three-day module to provide more time for discussion and practice. All providers recommended that the counseling job aids be introduced at other sites to strengthen antenatal education.

\section{Discussion}

Health information-sharing is an essential element of focused antenatal care. Yet, baseline study findings showed that although women had multiple antenatal visits, they were not profiting entirely from effective communication for care during and after pregnancy. While later pregnancy stage was correlated with increased knowledge at baseline, overall knowledge was poor despite repeated clinical contacts. Seventy percent of women in the study had more than one prior antenatal visit in the current pregnancy, and the majority had previous pregnancies. Yet, fewer than a quarter of women correctly identified components of birth preparedness and danger sign recognition compared to over a half to two-thirds at endline. Such low levels of awareness indicated a missed opportunity for health promotion during pregnancy. 
Table 5 Provider perceptions regarding use of counseling job aids (Intervention arm only)

\begin{tabular}{|c|c|c|c|c|c|}
\hline & Advantages to using counseling job aids: & & $\begin{array}{l}\text { Disadvantages to using counseling job } \\
\text { aids: }\end{array}$ & & $\begin{array}{l}\text { Suggestions to improve use } \\
\text { of counseling job aids: }\end{array}$ \\
\hline- & Pregnant women better retain messages* & - & $\begin{array}{l}\text { Requires additional time which delays } \\
\text { when the women leave the health center }\end{array}$ & - & $\begin{array}{l}\text { Improve durability of the } \\
\text { cards }\end{array}$ \\
\hline - & Health workers review all communication elements & - & Requires additional time for providers* & - & $\begin{array}{l}\text { Extend duration of training in } \\
\text { use of the cards }\end{array}$ \\
\hline - & Increases speed in which women grasp key messages & - & Too many cards; difficult to organize & - & $\begin{array}{l}\text { Decrease number of cards } \\
\text { used in each module* }\end{array}$ \\
\hline & $\begin{array}{l}\text { Cards function as a reminder ("job aid') for the health worker } \\
\text { of key messages* }\end{array}$ & & & - & $\begin{array}{l}\text { Increase number of messages } \\
\text { per card }\end{array}$ \\
\hline & $\begin{array}{l}\text { Relieves provider of burden to explain messages without } \\
\text { images }\end{array}$ & & & & \\
\hline- & $\begin{array}{l}\text { Less time is needed for explaining because the cards' images } \\
\text { assist in comprehension among women (saves time)* }\end{array}$ & & & & \\
\hline & Allows provider to master material over time & & & & \\
\hline & $\begin{array}{l}\text { Depicts danger signs and consequences of poor practices that } \\
\text { women can visualize }\end{array}$ & & & & \\
\hline & Women appreciate the cards & & & & \\
\hline
\end{tabular}

Note: The symbol $(*)$ denotes that providers commonly gave the response. All providers responded "yes" when asked whether they thought the counseling job aids should be introduced at other sites.

Results of this study showed that introduction of a job aids-focused intervention can improve quality of counseling and, in turn, maternal understanding when job aids are combined with training, field support, and site-level organizational changes. Findings demonstrated that communication content and techniques significantly improved following the intervention in such areas as birth preparedness, danger sign recognition, clean delivery, and newborn care. Improved communication was also associated with improved maternal knowledge in birth preparedness, danger signs, and delivery care. Maternal knowledge of newborn care also increased in the intervention arm, although this was not significant after adjusting for changes in the control arm. Few studies have examined what specific information is provided antenatally to women within the context of maternal and newborn care in a resource-poor African setting. This implementation research enabled intermediate results to be linked with communication processes and provided information on the relative effectiveness of a set of performance support tools for health care personnel. The results of the study support findings of earlier studies in which clinic-based health education coupled with job aids effectively improved quality of communication [24] and patient comprehension [31].

Although counseling quality improved in most topic areas, no relative gains in counseling were observed for messages regarding general prenatal care. This may have resulted because baseline levels in provider counseling as well as maternal knowledge were highest in this topic area. Providers in the intervention arm may not have placed as much priority on improving communication given perceptions that maternal knowledge was already adequate. Nonetheless, the job-aid focused intervention's observed improvements across most topics in the span of one clinical visit is encouraging and suggests that, following job aid-supported counseling, pregnant women are more equipped to make informed decisions regarding their health and that of their newborn.

Several factors likely contributed to the observed improvement in addition to provider training and field support. One potential factor is that the maternal and newborn care counseling aids were adapted to the Beninese environment and were easy to use. In their design as a practical aid for communication, they were consistent with existing skills and practices, easy to "try out," organized in modules (to prioritize messaging), and yielded visible results. These features have been shown to enhance the implementation of new practices [32,33]. The tools also provided clarity to provider communication goals and used locally relevant graphics to enhance the engagement of low-literate women [34].

A second factor relates to implementation of the intervention. Uptake in the use of job aids was high among providers, and the organizational sessions included the head nurse-midwife regardless of the extent of her involvement in antenatal communication. This was done to facilitate the introduction of site-level organizational changes needed to improve communication, particularly for organizing counseling sessions and ensuring adequate feedback mechanisms. Evidence shows that local leadership enhances the implementation of new practices [35], which is consistent with the programmatic experience of this study. 
Despite these achievements, the job-aid focused intervention was unable to mitigate all implementation barriers, which possibly explains why gains were moderate in some areas. During interviews, providers reported that lack of or limited dedicated space for counseling remained a challenge along with language barriers (in areas with multiple dialects). In addition, clinical tasks, such as managing deliveries, disrupted or prevented high quality antenatal communication. Lack of time was the most commonly reported barrier as providers recognized that good communication takes time. Recent studies have shown that duration of antenatal consultations is low in many developing countries with even less time spent on communication $[6,11]$. Within the intervention arm, there was a significant increase in the duration of antenatal consultations following introduction of the counseling job aids. Such an increase may not always be problematic [18]. In fact, the relatively modest increase was not perceived to be unmanageable, but the cited time barrier by providers for effective communication does deserve consideration. It is interesting to note that some health workers indicated that the images actually reduced the time needed for explanation, allowing them to increase the number of messages. However, the challenge of communicating effectively in relatively short periods of time still needs to be addressed.

Particularly in facilities where health personnel are understaffed or have multiple clinical responsibilities, one alternative may be to explore the feasibility and effectiveness of expanding the role of less skilled health workers who may have fewer time constraints. Nearly three-fourths of women in the intervention arm said they would have preferred having the provider spend more time with them for counseling (data not shown). This was higher than the proportion of women at baseline, perhaps resulting from an increased provision of information which raised interests and discussion preferences. It is also important to note that while the job aids-focused intervention was effective in standardizing communication, one drawback may be over-reliance on the tools that results in overly structured, less-individualized sessions. Efforts are needed to ensure that communication is still patient-centered and that counseling job aids are used as an aid, not a verbatim guide for communication.

\section{Limitations}

These findings should be interpreted in light of the study's limitations. One, due to the nature of the intervention, it was not operationally feasible to blind the data collection team regarding the intervention or control status of participating sites. Although supervisors observed a sample of counseling sessions for quality control purposes, some reporting biases may have occurred. Health workers may likewise have altered their behavior in response to being observed, which may have inflated documented performance levels. It is possible that cross contamination also led to an underestimation of the relative effect, although this is unlikely given efforts to only implement job aids-focused activities in intervention sites.

Two, the study did not assess whether improved counseling and maternal knowledge, in turn, led to improved home care practices among women, which was the basis for much of the information shared. Studies have shown that increased knowledge is not necessarily linked with behavior change [36], and there is still limited empirical demonstration of the effectiveness of some communication goals, such as birth preparedness, which was included in this study [37]. However, the research does demonstrate the intervention's direct effects on health worker behavior and maternal knowledge, which provides important insight on programmatic strategies to improve health outcomes. The counseling job aids were valued in their design as a practical tool in the intermediate step of communication, which arguably is crucial in empowering individual women to safeguard their health and that of their newborn.

Other possible limitations are that despite randomization of sites and similarities in demographic characteristics, there were significant differences in baseline quality of counseling between study arms, which may have accounted for differences in outcomes at endline. To adjust for this, data were evaluated using a difference-indifferences analysis, although it is possible that the observed intervention effect would be lower (or higher) in sites with dissimilar baseline performance levels. No specific reasons were identified to explain differential performance levels at baseline between the two study arms. In addition, several study sites were participating in a quality improvement initiative at the time of the study. As a result, they may have been more willing to introduce an improvement strategy and have been more apt to benefit from introduction of such as compared to sites without experience in quality improvement. Sub-analyses found no differences in counseling performance between sites participating in an improvement collaborative versus those who were not. This may have resulted since the improvement collaborative had not focused on antenatal counseling as part of its scope. Participation in the collaborative did not vary significantly between intervention and control arms. By design, the study was likewise unable to differentiate between the unique effect of the job aids in the intervention group as compared to the job aid training, organizational changes, and field support. Our findings thus represent an evaluation of a job aids-focused package of interventions than the tools alone. Lastly, the study did not assess the extent to which improved quality of 
counseling and maternal knowledge were maintained over time or enhanced as a result of repeated use of the counseling job aids throughout a woman's pregnancy. Qualitative research such as in-depth interviews with women participants would provide greater insight on effectiveness of communication over time.

\section{Implications}

Several policy and programmatic implications emerge from the study's findings. One, this study demonstrates that job aids with training, field support, and organizational change are an effective strategy for improving provider communication and should be integrated into routine antenatal care strategies. However, widespread implementation of the counseling aids will need to factor in how changes in communication activities influence other service areas. Our experience revealed that improved communication led to longer antenatal consultations. While it is plausible that increased efficiency using the cards may save time in the long run, such benefits have not yet been shown. Furthermore, broad scale implementation of the cards will require a functional supply management system beyond mechanisms used for this study, as well as consideration of the social norms that influence provider-patient interactions.

A second implication for practice relates to quality improvement. This study found that improving quality of communication was associated with increased maternal understanding in a relatively short period and that building capacity of health personnel with appropriate performance support was crucial in the process. Findings suggest that antenatal care programs should target strengthening communication to pregnant women as part of systematic improvement strategies. This should be combined with on-going quality assessment that identifies the kind of information given to women and its impact on their behavior and understanding.

Lastly, findings highlight that in practice women in advanced pregnancy can and need to be targeted for advice on newborn care. International guidelines emphasize the need to promote newborn care during the antenatal period, not just after birth [38]. Recent evidence demonstrates that antenatal health communication to promote evidence-based newborn care practices is effective in averting newborn mortality in developing countries [39]. The magnitude of antenatal clinical coverage in the developing countries means that pregnant women in many contexts can be advised on care of the newborn prior to birth along with maternal care during pregnancy and birth preparation.

\section{Conclusions}

Antenatal health counseling is an important strategy to promote awareness of maternal and newborn health during pregnancy, yet quality of communication is often poor and understudied. Findings from this study indicate that use of a job aids-focused intervention can be an effective strategy to improve quality of antenatal communication as well as maternal understanding. Efforts are needed to address time constraints and other barriers to communication, including introduction of on-going quality assessment and appropriate mechanisms for scale-up.

\section{Acknowledgements}

The authors are grateful to all the health personnel and pregnant and recently-delivered women who participated in the study, in addition to the data collectors, supervisors, technical and administrative staff of the Integrated Family Health Project (PISAF, Projet Intégré de Santé Familiale) who made this research possible. Special thanks to Tisna Veldhuijzen van Zanten, David Nicholas, Aguima Tankoano, Bart Burkhalter, Lynne Miller Franco, Yves Armand Mongbo, and the Benin Ministry of Health for their support to the development and implementation of the study; to Mandy Rose for her work in the development of the counseling job aids and training curriculum; to Kathleen Hill and Michelle Hindin for their technical support and guidance; and to Kurt Mulholland for his work in the job aids graphic design. This study was co-funded with resources received from the United States Agency for International Development (USAID) through the USAID Health Care Improvement Project (Contract No. GHN-I-0I-07-00003-00) and the Integrated Family Health Project Health Project (Contract No. 680-A00-06-00013-00), both managed by University Research Co., LLC (URC). All conclusions are those of the authors and do not necessarily reflect the views of the funding organizations.

\section{Author details}

${ }^{1}$ USAID Health Care Improvement Project, University Research Co., LLC, Bethesda, Maryland, USA. ²Department of Population, Family, and Reproductive Health, Johns Hopkins Bloomberg School of Public Health, Baltimore, Maryland, USA. ${ }^{3}$ Integrated Family Health Project, University Research Co., LLC, Bohicon, Benin.

\section{Authors' contributions}

$\sqcup J$ conceived and designed the study, developed the data collection instruments, supervised data collection, performed the statistical analysis, and wrote all versions of the manuscript. ASY and JA participated in the testing and finalization of the data collection instruments, carried out the job aids training, participated in data collection, coordinated field implementation, reviewed the study results, and made contributions to the manuscript. MA participated in the design of the job aids and associated training, reviewed study results, and made contributions to the manuscript. All authors read and approved the final manuscript.

\section{Competing interests}

The authors declare that they have no competing interests.

Received: 18 February 2010 Accepted: 22 November 2010 Published: 22 November 2010

\section{References}

1. World Health Organization: Standards for maternal and neonatal care. Provision of effective antenatal care. Geneva, Switzerland: World Health Organization; 2006 [http://www.who.int/making_pregnancy_safer/ publications/Standards1.6N.pdf], Retrieved April 2008 from URL.

2. Lawn J, Kerber K, eds: Opportunities for Africa's newborns: practical data, policy and programmatic support for newborn care in Africa. PMNCH, Cape Town; 2006.

3. Moran A, Sangli G, Dineen R, Rawlins B, Yameogo M, Baya B: Birthpreparedness for maternal health: findings from Koupela District, Burkina Faso. J Health Popul Nutr 2006, 24(4):489-97. 
4. Syed U, Asiruddin S, Helal S, Mannan I, Murray J: Immediate and early postnatal care for mothers and newborns in rural Bangladesh. $J$ Health Popul Nutr 2006, 24(4):508-518.

5. Harting J, van Assema $P$, van der Molen HT, Ambergen T, de Vries NK Quality assessment of health counseling: performance of health advisors in cardiovascular prevention. Patient Education and Counseling 2004, 54:107-118.

6. Anya SE, Hydara A, Jaiteh LE: Antenatal care in The Gambia: missed opportunity for information, education and communication. BMC Pregnancy and Childbirth 2008, 8:9.

7. Senaratha U, Fernandoa DN, Vimpanib G, Rodrigoc I: Factors associated with maternal knowledge of newborn care among hospital-delivered mothers in Sri Lanka. Trans R Soc Trop Med Hyg 2007, 101(8):823-30.

8. Telfer ML, Rowley JT, Walraven GE: Experiences of mothers with antenatal, delivery and postpartum care in rural Gambia. Afr J Reprod Health 2002, 6:74-83.

9. Beck R, Daughtridge R, Sloane P: Physician-patient communication in the primary care office: a systematic review. J Am Board Fam Pract 2002, 15(1):25-38, Review.

10. Rea MF, dos Santos RG, Sanchez-Moreno CC: Quality of infant feeding counseling for HIV+ mothers in Brazil: challenges and achievements. Acta Paediatrica 2007, 96:94-99.

11. Delva W, Mutunga L, Quaghebeur A, Temmerman M: Quality and quantity of antenatal HIV counseling in a PMTCT programme in Mombasa, Kenya. Aids Care 2006, 18(3):189-193.

12. Chopra M, Doherty T, Jackson D, Ashworth A: Preventing HIV transmission to children: quality of counseling of mothers in South Africa. Acta Paediatr 2005, 94(3):357-363.

13. Nobile C, Drotar D: Research on the quality of parent-provider communication in pediatric care: implications and recommendations J Dev Behav Pediatr 2003, 24(4):279-290, Review.

14. Harvey SA, Jennings L, Chinyama M, Masaninga F, Mulholland K, Bell D: Improving community health worker use of malaria rapid diagnostic tests in Zambia: package instructions, a job aid, and job aid-plustraining. Malaria Journal 2008, 7:160-172.

15. Rennie W, Phetsouvanh $R$, Lupisan S, Vanisaveth $V$, Hongvanthong $B$, Phompida S, Alday P, Fulache M, Lumagui R, Jorgensen P, Bell D, Harvey S: Minimising human error in malaria rapid diagnosis: clarity of written instructions and health worker performance. Trans $R$ Soc Trop Med Hyg 2007, 101:9-18.

16. Leshabari S, Koniz-Booher P, Burkhalter B, Hoffman M, Jennings L: Testing a PMTCT Infant-feeding Counseling Program in Tanzania. Operations Research Results Published for the U.S. Agency for International Development (USAID) by QAP; 2007 [http://www.hciproject.org/node/984], Retrieved 13 November 09 from URL.

17. Kim YM, Davila C, Tellez C, Kols A: Evaluation of the World Health Organization's family planning decision-making tool: improving health communication in Nicaragua. Educ Couns 2007, 66(2):235-242, Patient.

18. Leon F, Brambila C, de la Cruz M, Garcia C, Moarles C, Vasquez B: Providers' compliance with the balanced counseling strategy in Guatemala. Stud Fam Plann 2005, 36(2):117-126.

19. Knebel E: The use of manual job aids by health care providers: what do we know? Issue Paper Published for USAID by QAP; 2000 [http://www. hciproject.org/node/616], Retrieved April 2008 from URL: http://www. qaproject.org/pubs/PDFs/ISSUESJA.PDF.

20. Rossett A, Gautier-Downes J: A Handbook of Job Aids San Francisco: JosseyBass/Pfeiffer. John Wiley \& Sons; 1991

21. Edward-Raj A, Phiri R: Assessing the functionality of job aids in supporting the performance of $\mathrm{IMCl}$ providers in Zambia. In Operations Research Results. Volume 2. Bethesda, MD: Published for USAID by QAP; 2002(8) [http://www.hciproject.org/node/538], Retrieved April 2008 from URL: http://www.qaproject.org/pubs/PDFs/JobAidZambia.pdf.

22. Gilroy K, Winch PJ, Diawara A, Swedberg E, Thiero F, Kane M, Daou Z, Berthe $Z$, Bagayoko A: Impact of $I M C I$ training and language used by provider on quality of counseling provided to parents of sick children in Bougouni District, Mali. Patient Educ Couns 2004, 54:35-44.

23. Winch $\mathrm{P}$, Bagayoko A, Diawara A: Increases in correct administration of chloroquine in the home and referral of sick children to health facilities through a community-based intervention in Bougouni District, Mali. Trans R Soc Trop Med Hyg 2003, 97(5):481-490.
24. Zaman S, Ashraf RN, Martines J: Training in complementary feeding counseling of healthcare workers and its influence on maternal behaviours and child growth: a cluster-randomized controlled trial in Lahore, Pakistan. J Health Popul Nutr 2008, 26(2):210-222.

25. Demographic and Health Survey: Benin; 2006

26. USAID Health Care Improvement Project: The Improvement Collaborative: An Approach to Rapidly Improve Health Care and Scale Up Quality Services. 2008 [http://www.hciproject.org/node/1057], Retrieved 07 April 2009 from URL: http://www.hciproject.org/methods\&tools/hcicollab.html.

27. Alderman H, Ndiaye B, Linnemayr S, Ka A, Rokx C, Dieng K, MulderSibanda M: Effectiveness of a community-based intervention to improve nutrition in young children in Senegal: a difference in difference analysis. Public Health Nutrition 2009, 12(5):667-73.

28. Reichardt CS: The statistical analysis of data from non-equivalent group designs. In Quasi-experimentation: Design and Analysis Issues for Field Settings. Edited by: Thomas D Cook, Donald T Campbell. Chicago: Rand McNally; 1979:147-205.

29. Hox J: Multilevel Analysis. Techniques and applications New Jersey: Lawrence Erlbaum and Associates, Inc; 2002.

30. Snijders TB, Bosker RJ: Mulitlevel analysis: an introduction to basic and advanced multilevel modeling Thousand Oaks, California: Sage Publications Inc; 1999.

31. Perreira KM, Bailey PE, de Bocaletti E, Hurtado E, de Villagrán SR, Matute J: Increasing awareness of danger signs in pregnancy through communityand clinic-based education in Gautemala. Maternal and Child Health Journal 2002, 6(1):19-28.

32. Veldhuijzen $W$, Ram PM, van der Weijden $T$, Niemantsverdriet $S$, van der Vleuten CP: Characteristics of communication guidelines that facilitate or impede guideline use: a focus group study. BMC Family Practice 2007 8:31.

33. Grol R, Wensing M, Eccles M: Improving patient care: the implementation of change in clinical practice. Elsevier Boston: Butterworth-Heinemann; 2005.

34. Houts PS, Doak CC, Doak LG, Loscalzo MJ: The role of pictures in improving health communication: a review of research on attention, comprehension, recall and adherence. Patient Educ Couns 2006, 61(2):173-190.

35. Catsambas TT, Franco LM, Gutmann M, Knebel E, Hill P, Lin Y-S: Evaluating Health Care Collaboratives: The Experience of the Quality Assurance Project. Collaborative Evaluation Series. Published by the USAID Health Care Improvement Project. Bethesda, MD: University Research Co., LLC (URC); 2008 [http://www.hciproject.org/node/1057], Retrieved 13 November 09 from URL.

36. Khadduri R, Marsh DR, Rasmussen B, Bari A, Nazir R, Darmstadt GL: Household knowledge and practices of newborn and maternal health in Haripur district, Pakistan. Journal of Perinatology 2008, 28:182-187.

37. Stanton C: Methodological issues in the measurement of birth preparedness in support of safe motherhood. Evaluation Review 2004, 28:179-200.

38. Neonatal Mortality Formative Research Working Group: Developing community-based intervention strategies to save newborn lives: lessons learned from formative research in five countries. Journal of Perinatology 2008, S2-S8.

39. Baqui AH, El-Arifeen S, Darmstadt G, Ahmed S, Williams EK, Seraji HR, Mannan I, Rahman SM, Shah M, Saha S, Syed U, Winch P, Lefevre A, Santosham M, Black RE, for the Projahnmo Study Group: Effect of community-based newborn care intervention package implemented through two service-delivery strategies in Sylhet district, Bangladesh: a cluster-randomised controlled trial. Lancet 2008, 371:1936-1944.

\section{Pre-publication history}

The pre-publication history for this paper can be accessed here: http://www.biomedcentral.com/1471-2393/10/75/prepub

doi:10.1186/1471-2393-10-75

Cite this article as: Jennings et al:: Antenatal counseling in maternal and newborn care: use of job aids to improve health worker performance and maternal understanding in Benin. BMC Pregnancy and Childbirth 2010 10:75. 